\title{
O PAPEL DA LEGÍSTICA NA (RE)LEGITIMAÇÃO DAS DECISÕES JUDICIAIS E NO EQUILÍBRIO DO EXERCÍCIO DA FUNÇÃO JUSPOLÍTICA PELOS TRIBUNAIS*
}

\author{
THE ROLE OF LEGISTICS IN (RE)LEGITIMATION OF JUDGMENTS AND IN \\ BALANCING THE JUSPOLITICAL FUNCTIONS OF COURTS
}

\author{
Rafael de Oliveira Costa**
}

\begin{abstract}
RESUMO
O presente estudo busca repensar o problema da racionalidade e legitimidade das decisões judiciais sob a égide da legística material, revelando-se de grande utilidade para uma compreensão mais profunda do fenômeno do poder criativo do direito e priorizando o questionamento acerca do próprio papel desse ramo do conhecimento (não mais limitado ao estudo de métodos adequados para a elaboração da norma). Assim é que, à luz da avaliação de impacto e partindo de um "ponto de vista hermenêutico", sustentamos que a legística material pode contribuir decisivamente para a delimitação da função juspolítica exercida pelos tribunais, ajudando a estabelecer as atribuições dos Poderes constituídos e a determinar o papel do Judiciário e do Legislativo no contexto hodierno, sem prejuízo da responsabilização do legislador pela elaboração de proposições normativas que não produzam os efeitos esperados.
\end{abstract}

\section{PALAVRAS-CHAVE}

Função juspolítica dos tribunais. Legística material. Responsabilidade do legislador.

\begin{abstract}
This study seeks to rethink the problem of rationality and legitimacy of judicial decisions under the contributions of legistics, revealing useful for a deeper understanding of the phenomenon of the creative power of Judiciary and inaugurating a new approach that prioritizes the questioning about the proper role of legistics (no longer limited to study methods). Bearing in mind impact assessment and from an "hermeneutical point of view", we hold that legistics decisively contributes to an adequate delineation of the juspolitical function performed by courts, helping to establish the duties of constituted Powers and the current role of Judiciary and Legislative, without disregarding the responsibility of legislators when drafting normative propositions that do not produce the expected effects.
\end{abstract}

\section{KEYWORDS}

Legistics. Juspolitical function of courts. Legislator’s responsibilities.

\footnotetext{
* O autor agradece aos revisores anônimos da revista, em razão das inúmeras contribuições para a objetividade e cientificidade do presente trabalho.

** Professor visitante na Universidade da Califórnia-Berkeley (EUA). Doutor e Mestre em Direito pela Faculdade de Direito da UFMG. Graduação em Direito pela Faculdade de Direito da UFMG (2007), em programa conjunto com a University of Wisconsin-Madison (EUA - 2005). Promotor de Justiça no Estado de São Paulo (Leme, SP, Brasil). Email: rafaelcosta22000@gmail.com
} 


\section{INTRODUÇÃO}

A legística ou legisprudência, enquanto área do conhecimento que se ocupa do fazer dos atos normativos, almeja aprimorar a qualidade da legislação. Esse ramo divide-se basicamente em duas grandes áreas: a legística material e a legística formal. A legística material abrange o processo analítico relacionado ao conteúdo das leis, ao passo que a legística formal é responsável pela chamada “técnica legislativa” (CANOTILHO, 1991, p. 7-8).

No presente estudo confere-se especial atenção à legística material, que procura incorporar uma perspectiva crítica ao processo de elaboração da legislação, atentando para a qualidade dos atos normativos e priorizando a eficácia/efetividade das normas. Superando a concepção clássica de ramo do conhecimento que se limita a buscar métodos e técnicas (legística formal), busca-se repensar o problema da racionalidade e legitimidade das decisões judiciais. Para tanto, assume-se como premissa o fato de que o aplicador do direito não pode desconsiderar o momento do "fazer legislativo” ao interpretar a norma. As decisões jurídicas precisam ser dotadas de uma pretensão de correção, integridade e coerência que permita sustentar a opção realizada não apenas na própria autoridade (o que lhe confere certo grau de legitimidade formal), mas na adoção de procedimento adequado (o que também contribui para sua legitimação formal), na racionalidade da argumentação (legitimação formal) e no conteúdo da norma a ser aplicada (legitimação material).

A análise do tema se desenvolverá em quatro partes. Em um primeiro momento, iremos nos concentrar nas razões que motivam a adoção de uma perspectiva crítica na tarefa de legislar. A segunda parte apresentará as contribuições da legística material para a teoria da separação dos poderes. O tópico seguinte fará uma análise da responsabilidade do legislador na perspectiva clássica. Por fim, a parte quatro propõe uma nova forma de responsabilização e sustenta que a legística desempenha papel primordial na relegitimação das decisões judiciais.

Assim, à luz da avaliação de impacto e partindo de um “ponto de vista hermenêutico”, sustentamos que a legística material pode contribuir decisivamente para a delimitação da função juspolítica exercida pelos tribunais, ajudando a estabelecer as atribuições dos Poderes constituídos e a determinar o papel do Judiciário e do Legislativo no contexto hodierno, sem prejuízo da responsabilização do legislador pela elaboração de proposições normativas que não produzam os efeitos esperados.

Esse é o nosso plano de estudos. Passemos à sua concretização. 


\section{EM BUSCA DA PERSPECTIVA CRÍTICA NA TAREFA DE LEGISLAR}

Por que apenas agora os juristas atentaram para a importância da legisprudência?

Objetivando responder a essa indagação, o professor Luc Wintgens, da Universidade de Yale e de Bruxelas, aduz que o direito se separa da política por uma razão epistemológica, ou seja, quanto à análise do objeto de estudo. E isso porque existia, até recentemente, "um vazio nas relações entre o Direito Natural e o Direito Positivo” (WINTGENS, 2000, p. 116-117). Vazio, este, que decorria dos diferentes fundamentos de legitimidade atribuídos ao direito positivo durante o seu desenvolvimento histórico (WINTGENS, 2000, p. 123).

O primeiro fundamento de legitimidade atribuído ao direito positivo, baseado no direito comum romano, concebia o fenômeno jurídico de forma casuística, ou seja, baseado nos costumes (WINTGENS, 2000, p. 123-128). Posteriormente, um novo fundamento de legitimidade, baseado no direito natural, foi atribuído ao direito positivo, com o intuito de garantir a abstração, a racionalidade e a universalidade das normas: o conteúdo do direito, segundo essa concepção, era ditado por uma norma "transcendente ou superior", fazendo com que a tarefa de aplicação do direito fosse absorvida pela tarefa de criação da norma (VILLEY, 2005, p. 76), mas permitindo simultaneamente avanços em termos de publicidade da administração da justiça (WINTGENS, 2000, p. 117-121). Por fim, Wintgens aduz que o fundamento “positivista” sustenta-se na teoria da separação dos poderes e atribui a tarefa de criar o direito ao legislador soberano: o juiz limita-se a aplicar a norma, numa verdadeira “atitude de aplicação” ${ }^{1}$ (WINTGENS, 2000, p. 118-121).

Nesse sentido, o impulso para legislar (ou seja, os motivos políticos, jurídicos e sociais que podem justificar o início do procedimento legislativo $)^{2}$ tem natureza política e encontra respaldo no legalismo, que pode ser definido como a "atitude ética segundo a qual a conduta moral é uma questão de se submeter às regras” (WINTGENS, 2000, p. 118).

Assim, para entender o contexto em que se deu o aparecimento da legística, é preciso traçar primeiramente a distinção entre o legalismo forte e o legalismo fraco (WINTGENS, 2000, p. 118). Para o legalismo forte, a legalidade é uma condição necessária e suficiente para a existência e o sentido do direito (WINTGENS, 2000, p. 128-130). Segundo os defensores dessa concepção, o fenômeno jurídico é caracterizado pela atemporalidade, pelo estatismo e pela utilização do método científico (WINTGENS, 2000, p. 128-130).

\footnotetext{
${ }^{1}$ Vale ressaltar que, ao propor a distinção entre legalismo forte e legalismo fraco, Wintgens realiza uma simplificação das diversas teorias existentes. Em razão das dimensões deste estudo, remetemos o leitor à seguinte obra: BOBBIO, Norberto. O positivismo jurídico: lições de filosofia do direito. São Paulo: Editora Ícone, 1995.

${ }^{2}$ Acerca do tema, vale a pena conferir: SILVA, José Afonso da. Processo Constitucional de Formação das Leis. 2. ed. São Paulo: Malheiros, 2006.
} 
De outro modo, para o legalismo fraco, a legalidade ou validade formal é apenas uma condição necessária, mas não suficiente, para a existência de uma norma. Deve ser rejeitada a ideia de que as normas possuem um sentido em si. O direito é caracterizado pela temporalidade, socialidade e não logicismo (WINTGENS, 2000, p. 128-130). Em outras palavras, não existe uma “teoria representativa da realidade”, mas “teorias sobre a realidade” (WINTGENS, 2000, p. 128130). Essa concepção permitiu o surgimento de questionamentos pela doutrina que culminaram na aparição da legística, uma vez que a racionalidade na elaboração dos atos normativos deixou de ser algo dado, a priori, e passou a ser concebida como um problema de "justificação do impulso para legislar” (WINTGENS, 2000, p. 130).

\begin{tabular}{|c|c|}
\hline Legalismo Forte & Legalismo Fraco \\
\hline $\begin{array}{c}\text { A criação e a aplicação das } \\
\text { normas são consideradas } \\
\text { uma reprodução da } \\
\text { realidade. }\end{array}$ & $\begin{array}{c}\text { A criação e a aplicação das } \\
\text { normas são apenas uma } \\
\text { construção e nunca uma } \\
\text { reprodução da realidade. }\end{array}$ \\
\hline $\begin{array}{c}\text { A racionalidade do } \\
\text { legislador é uma } \\
\text { presunção. }\end{array}$ & $\begin{array}{c}\text { A racionalidade do } \\
\text { legislador é um problema } \\
\text { de justificação. }\end{array}$ \\
\hline $\begin{array}{c}\text { Os juízes aplicam as } \\
\text { normas que os legisladores } \\
\text { criaram. }\end{array}$ & $\begin{array}{c}\text { Os juízes e o legislador } \\
\text { criam e aplicam normas. }\end{array}$ \\
\hline
\end{tabular}

A partir dessa distinção, conclui Wintgens que qualquer crítica ao legalismo deve ser feita sob um ponto de vista externo, pois uma crítica sob a égide normativa (ponto de vista interno) se afigura impossível (WINTGENS, 2000, p. 130-131). Por este motivo, a legisprudência deve 1) adotar técnicas legislativas para redação do texto; 2) usar a sociologia do direito para valoração das conquistas, aumentando o nível de confiança nas instituições (dialogicidade legislativa) e 3) adotar processos de avaliação legislativa (WINTGENS, 2000, p. 117-120). ${ }^{3}$ Além disso, a Teoria da Legislação deve buscar a racionalidade na tarefa de legislar. Mas como alcançar essa racionalidade?

Em primeiro lugar, o legislador deve levar em consideração os aspectos interno e externo

\footnotetext{
${ }^{3}$ Diante desses objetivos, resta evidente a tensão entre o técnico e o político: enquanto o técnico deve respeitar o direito posto, o político precisa estar atento ao que está acontecendo na sociedade, atuando de forma a adaptá-lo às necessidades da coletividade (SILVA, 2006).
} 
da norma, ou seja, deve partir de um "ponto de vista hermenêutico” (WINTGENS, 2000, p. 132). Trata-se de uma perspectiva que abrange simultaneamente o ponto de vista externo do observador e o ponto de vista interno do ator, ou seja, expressa a ideia de que, para criar proposições normativas, não podemos nos basear apenas em conceitos objetivos, mas devemos partir do próprio ordenamento jurídico. Dito de outro modo, não existe uma separação rígida entre o sentido interno (dado pelo ordenamento jurídico) e o sentido externo (obtido, por exemplo, pela sociologia ou pela psicologia). Os sentidos encontram-se conectados. Em suma, o intérprete deve buscar, sem qualquer vinculação com a sua própria consciência e a partir do ordenamento jurídico, o sentido da norma interpretanda.

Em segundo lugar, o legislador deve se basear em uma perspectiva legisprudencial fixando os fatos adequadamente, analisando as diferentes alternativas existentes e promovendo a avaliação prospectiva e retrospectiva dos efeitos da norma (WINTGENS, 2000, p. 132-133). A legística material deve levar o legislador, antes de positivar a norma jurídica, a pensá-la, sob uma perspectiva crítica, para solução dos conflitos existentes ${ }^{4}$, atentando para sete grandes fases: 1) problematização do impulso legiferante; 2) fixação dos objetivos a serem atingidos com a norma; 3) estabelecimento de cenários alternativos (ou princípio da alternatividade); 4) escolha das soluções possíveis ${ }^{5}$; 5) avaliação prospectiva da positivação da norma; 6) execução e 7) avaliação de impacto retrospectiva ${ }^{6}$. Em suma, a legística material se interessa pelo momento em que a norma ainda não é “válida” e, nesta encruzilhada entre os mundos do direito e da política, revela toda a sua potencialidade, atuando de forma decisiva para que a norma tenha eficácia e efetividade verdadeiro desafio contemporâneo no âmbito constitucional e infraconstitucional.

Ademais, a premissa de que todo raciocínio jurídico parte de um "ponto de vista hermenêutico” exalta a hermenêutica, que assume um papel relevantíssimo não só no exercício da função jurisdicional, mas também no exercício da função legislativa ${ }^{7}$, uma vez que permite o

\footnotetext{
${ }^{4}$ Cf. DELLEY, Jean Daniel. Pensar a Lei. Introdução a um Procedimento Metódico. Cadernos da Escola do Legislativo. Belo Horizonte, v. 7, n. 12, jan./jun. 2004.

${ }^{5}$ Para a escolha das soluções possíveis, o legislador deve levar em consideração os seguintes princípios: a) princípio da subsidiariedade do impulso para legislar (a positivação de uma nova norma só deve ocorrer quando as instituições existentes não são capazes de solucionar o problema); b) princípio da simplicidade (a nova proposição normativa deve evitar a complexidade); c) princípio da adequação (deve-se evitar a conduta arbitrária, aprovando-se proposições normativas que estejam em consonância com o objeto a ser normatizado) (DELLEY, Jean-Daniel. Pensar a Lei: uma introdução a um procedimento metódico. In: Cadernos da Escola do Legislativo, Belo Horizonte, v. 7, n. 12, p. 101143, jan./jun. 2004).

${ }^{6}$ Cf. DELLEY, Jean Daniel. Pensar a Lei. Introdução a um Procedimento Metódico. Cadernos da Escola do Legislativo. Belo Horizonte, v. 7, n. 12, jan./jun. 2004.

${ }^{7} \mathrm{O}$ que diferencia, em sua essência, a função jurisdicional da função legislativa? A diferença entre elas está na maior liberdade que possui o legislador (WINTGENS, 2000, p. 132). Segundo Wintgens (2000, p. 132-133), tanto o juiz como o legislador adotam um "ponto de vista hermenêutico" perante o direito, sofrendo uma limitação, pelas regras constitucionais, do poder de decidir. Contudo, este último possui uma esfera maior de liberdade (“discricionariedade
} 
diálogo legislação-racionalidade-aplicação da norma e a consolidação do fenômeno jurídico como uno e indivisível ${ }^{8}$.

Vale ressaltar que o termo legislação deve ser entendido em sentido amplo, abarcando, inclusive, o poder normativo da Administração Pública ${ }^{9}$. Isso porque, indiscutivelmente, certos agentes públicos têm competência para editar atos normativos, desde que compatíveis com a lei e com a Constituição. Embora a atribuição normativa regulamentar esteja entre as privativas do Presidente da República (art. 84, IV, da CF) e, por simetria, aos chefes dos Executivos dos estados, do Distrito Federal e dos municípios, outros agentes públicos (e.g., Ministros de Estados - art. 87, II, da Constituição) e determinados órgãos/pessoas jurídicas (e.g., agências reguladoras ${ }^{10}$ ) também têm poderes para fazê-lo.

Assim, em razão da natureza que apresentam, esses atos normativos devem observar regime jurídico semelhante ao da lei (artigo $1^{\circ}$, da Lei Complementar 95/98) no que diz respeito à técnica legislativa, à vigência, à publicação e à nulidade, razão pela qual os ensinamentos da legística material tornam-se indispensáveis para que sejam editadas normas eficazes, eficientes e efetivas. Em outras palavras, a legística material deve servir de fundamento não apenas para o legislador, mas também para a administração pública (e.g., na edição de portarias, resoluções, decretos, entre outros) e para os tribunais (e.g., na edição de resoluções pelo TSE, na prolação de decisões em mandado de injunção com efeitos concretos, entre outros), uma vez que permite a adoção de uma perspectiva crítica em todo e qualquer procedimento de elaboração de proposições normativas.

Nesse diapasão, incumbe ressaltar que o tempo da representatividade (ou seja, o período de duração dos mandatos) dificulta a adoção da racionalidade na tarefa de legislar, em razão da complexidade prática que permeia o processo de elaboração da norma. Ao contrário de representar um óbice, a legística suscita, novamente, antigos questionamentos acerca da duração dos mandatos, temática que ultrapassa os limites deste estudo.

política”), o que o diferencia do primeiro.

${ }^{8}$ A unidade e indivisibilidade do fenômeno jurídico representa, em verdade, a fusão dos momentos de criação, compreensão, interpretação e aplicação da norma, afastando a análise estanque e compartimentada que vem sendo promovida por inúmeros operadores do direito. Para tanto, a produção legislativa deve seguir a realidade concreta de seu tempo, uma vez que quando as leis se encontram em harmonia com a realidade que "juridicizam", passam a ser eficazes, transformando o próprio contexto que lhes deu origem. Trata-se do embate entre a força normativa do real (JELLINEK, 1991) e a força normativa da constituição (HESSE, 1991), que deve ser bem compreendido por aquele que deseja editar atos normativos eficazes, eficientes e efetivos.

9 Sem pretender ingressar em embate terminológico, utilizaremos neste trabalho a expressão poder normativo em sentido amplo, para abranger qualquer ato normativo editado pela administração pública.

${ }^{10}$ Urge frisar que existem dois limites ao exercício do poder normativo pelas agências reguladoras: a) os atos normativos não podem contrariar regras fixadas na legislação e b) é vedada a edição, pelas agências, de atos administrativos gerais e abstratos. 
Contudo, devidamente estabelecida a indispensabilidade da adoção de uma perspectiva crítica na tarefa de legislar, passemos à análise dos aportes da legística para a teoria da separação dos poderes.

\section{DA CONTRIBUIÇÃO DA LEGÍSTICA PARA UM NOVO EQUILÍBRIO NA SEPARAÇÃO DOS PODERES}

A questão acerca da criação de normas jurídicas pelo Judiciário ganhou especial relevo a partir da Revolução Francesa. Amostra dessa tendência recaiu no Título III, Capítulo V, da Constituição de 3 de setembro de 1791, cujo art. $3^{\circ}$ dispunha que "os tribunais não podem nem se imiscuir no exercício do Poder Legislativo, ou suspender a execução das leis, nem empreender funções administrativas, ou convocar diante deles os administradores por razão das funções destes”.

Movimento em direção contraposta surgiu ainda em plena ebulição do liberalismo político. Marco disso foi o art. $4^{\circ}$ do Código Civil francês de 1804, ao dispor que "o juiz que se recusar de julgar sob pretexto do silêncio, da obscuridade ou da insuficiência da lei, poderá ser demandado como culpado de denegar justiça”.

Essa nova posição, irrompida para fazer frente aos pregoeiros do rechaço radical à possibilidade da criação judicial do direito, deveu-se, como noticia Ross, a Portalis, que em seu Discurso Preliminar sustentou que a lei não é a única fonte do fenômeno jurídico (ROSS, 1999, p. 92-93). Portalis advogou a ideia de que, na tarefa de criação do direito, existe lugar também para as decisões prolatadas pelos juízes, reconhecendo na tarefa de julgar uma atividade independente e criadora (ROSS, 1999, p. 92-93).

O juiz, esse "ente inanimado", de que falava Montesquieu, tem sido na realidade a alma do progresso jurídico, o artífice laborioso do direito novo contra as fórmulas caducas do direito tradicional. Esta participação do juiz na renovação do direito é, em certo grau, um fenômeno constante, podia dizer-se uma lei natural da evolução jurídica: nascido da jurisprudência, o direito vive pela jurisprudência, e é pela jurisprudência que vemos muitas vezes o direito evoluir sob uma legislação imóvel (CRUET, 1956, p. 24) ${ }^{11}$.

\footnotetext{
${ }^{11}$ Não se pode, contudo, associar à atividade jurisprudencial a ideia de “progresso contínuo”, uma vez que, embora capaz de produzir transformações, atua também de modo a impedir o acolhimento de determinados valores e interesses. Daí por que se afigura possível classificar as cortes em “progressistas” ou “conservadoras”. E mais: "Estamos todos familiarizados com a maneira como a arbitrariedade da decisão majoritária no parlamento ou no congresso é citada como uma maneira de realçar a legitimidade das cartas de direitos e da revisão judicial. No fim, naturalmente, é uma estratégia sem esperança para os oponentes do majoritarismo. Os próprios tribunais de recursos são, invariavelmente, corpos de múltiplos membros que geralmente discordam entre si, mesmo após deliberação (Talvez especialmente após deliberação!). E, quando discordam, também eles tomam suas decisões por meio do voto e da decisão majoritária. Cinco votos derrotam quatro na Suprema Corte dos Estados Unidos. A diferença, quando uma questão é deslocada da legislatura para o tribunal, é uma diferença de grupos de constituintes, não uma diferença de método de decisão. Portanto, se votar produz resultados arbitrários sob o princípio da decisão majoritária, então, boa parte do direito constitucional norte-americano é arbitrário. Como assinalam Dan Farber e Philip Frickey no excelente estudo Law and Public Choice [Direito e opção pública], se pensamos (por exemplo, por razões associadas aos paradoxos de escolha
} 
Acontece, contudo, que a criatividade e a racionalidade da decisão judicial andam juntas e se encontram intimamente vinculadas à sua legitimidade. A decisão não é racional em si, mas decorre da possibilidade de sua verificação (PECZENIK, 2009). A argumentação, meio pelo qual se expressam as razões da decisão, contribui para sua legitimidade, demonstrando a sensibilidade e a coerência do decidido. Assim, o que legitima a aplicação do direito não é a decisão em si, mas a observância ao "devido processo decisório” e a adequada exegese de norma aprovada segundo os ditames da legística. Não se trata de resgatar os ensinamentos da Escola da Exegese, afastando qualquer atividade criativa exercida pelo juiz. Ao contrário, à luz das tendências contemporâneas da Teoria do Direito, é preciso buscar a interpretação adequada ao caso concreto, sem desconsiderar o princípio do livre convencimento motivado e a atividade “criadora” desempenhada pelo julgador. E mais: aqueles que irão sofrer os efeitos da decisão devem poder participar efetivamente de sua construção e devem ter acesso aos fundamentos que foram adotados para se chegar a um determinado resultado ${ }^{12}$.

Nesse contexto, a proposta de repensar o problema da racionalidade e legitimidade das decisões judiciais sob a égide da legística material e a partir de um "ponto de vista hermenêutico" revela-se de grande utilidade para uma compreensão mais profunda do fenômeno do poder criativo do direito pelo Judiciário, pois inaugura um novo enfoque que prioriza o questionamento acerca do próprio papel da legística (não mais limitada ao estudo de métodos adequados para a elaboração da norma, como pretende a legística formal) e da hermenêutica. As decisões jurídicas precisam ser dotadas de uma pretensão de correção, integridade e coerência que permita sustentar a opção realizada não apenas na própria autoridade (o que lhe confere certo grau de legitimidade formal), mas na adoção de procedimento adequado (o que também contribui para sua legitimação formal), na racionalidade da argumentação (legitimação formal) e no conteúdo da norma a ser aplicada (legitimação material). E é neste último momento que a legística material assume especial relevo, permitindo, a partir de uma perspectiva crítica, o diálogo entre o ponto de vista interno e o externo, entre o direito e o político, de modo a legitimar o decidido pelo conteúdo da proposição normativa a ser aplicada pelo operador do direito ${ }^{13}$.

social) que “o caos e a incoerência são os resultados inevitáveis da votação majoritária, então, os tribunais de recursos [...] foram igualmente à bancarrota [...] Se aceitamos a tese no que diz respeito às legislaturas, não temos para onde nos voltar” (WALDRON, 2003, p. 156-157).

${ }^{12}$ Sobre a legitimidade e congruência na decisão, conferir: GÜNTHER, Klaus. Un Concepto Normativo de Coherencia para una Teoría de la Argumentación Jurídica. Trad. Juan Carlos Velasco Arroyo. In: Doxa, 17-18, 1995, Alicante, p. 271-302; COSTA, Rafael de Oliveira. Horizontes Jusfilosóficos da Previsibilidade das Decisões Judiciais. In: Novos Estudos Jurídicos, v. 20, n. 2, p. 561-594, 2015.

${ }^{13}$ Conforme ficará claro mais à frente neste trabalho, a principal via para que seja possível a legitimação pelo conteúdo é a avaliação de impacto, instrumento que permite a análise da relação finalidade/efeitos da proposição normativa. 
Diante dessa mudança de paradigma, não se pode desconsiderar o impacto das revelações trazidas pela legística material para o controle da atividade criativa do direito exercida pelo Judiciário e, consequentemente, para a teoria da separação dos poderes.

A jurisdição constitucional, indispensável para o estabelecimento desse equilíbrio, deve realizar a sua construção não como um espaço para a prática de “arbitrariedades”, mas, ao contrário, deve servir ao controle da interpretação e da responsabilidade dos juízes, que se encontram submetidos aos limites trazidos por diplomas normativos de qualidade ${ }^{14}{ }^{15}$. Daí por que é preciso “fundamentar a fundamentação”: o direito não é casuísmo, mas produto da análise de casos concretos e de suas peculiaridades, para os quais devem ser dadas respostas coerentes e íntegras com os precedentes, a partir de uma adequada avaliação (prospectiva e retrospectiva) dos impactos do ato normativo editado e da construção participativa das partes na prolação da decisão ${ }^{16}$.

A legística material pode propiciar, ao Judiciário, balizas adequadas e compatíveis com as necessidades da sociedade, evitando que o aplicador ingresse na esfera de atuação do legislador, mediante a adoção de um "ponto de vista hermenêutico" que permite, a partir da avaliação de impacto, o diálogo legislação-racionalidade-aplicação da norma e a consolidação do fenômeno jurídico como uno e indivisível. Assim, quando a legística não é “levada a sério”, o Judiciário amplia o seu campo de atuação, e a sua postura criativa torna-se ainda mais evidente ${ }^{17}$.

Não se pode confundir, contudo, ativismo judicial com criação judicial do direito. A compreensão acerca do poder criador do juiz, enquanto instrumento em condições de atribuir dinâmica a um direito estático produzido pelo legislador, abrange a vasta gama de desafios posta pelo ativismo judicial:

O ativismo judicial representa, em última instância, a deslegitimação da Política em relação à sua tarefa essencial de buscar a realização dos valores determinados pela sociedade no

\footnotetext{
${ }^{14}$ Acerca do papel da hermenêutica constitucional, conferir: DWORKIN, Ronald. Levando os Direitos a sério. Trad. Nelson Boeira. São Paulo: Martins Fontes, 2002; COSTA, Rafael de Oliveira. Segurança Jurídica e Hermenêutica Constitucional: Horizontes Jusfilosóficos da Previsibilidade das Decisões Judiciais. 183p. 2009. Dissertação (Mestrado em Direito) Faculdade de Direito, Universidade Federal de Minas Gerais, Belo Horizonte, 2009; MÜLLER, Friedrich. Teoria Estruturante do Direito. São Paulo: Revista dos Tribunais, 2008.

${ }^{15}$ A busca pela racionalidade da decisão encontra respaldo na busca pela "fundamentação da fundamentação”, ou seja, na busca pelo fundamento do próprio ato de decidir à luz da Constituição (STRECK, 2006). Cf. COSTA, Rafael de Oliveira. A Criatividade e a Responsabilidade no Ato de Julgar: Aportes da Hermenêutica Fenomenológica para a Jurisdição Constitucional. 201p. 2013. Tese (Doutorado em Direito) Faculdade de Direito, Universidade Federal de Minas Gerais, Belo Horizonte, 2013.

${ }^{16}$ Cf. STRECK, Lenio Luiz. Verdade e Consenso: Constituição, hermenêutica e teorias discursivas. Rio de Janeiro: Lumen Juris, 2006. E ainda: DWORKIN, Ronald. O império do Direito. Trad. Jefferson Luiz Camargo. São Paulo: Martins Fontes, 1999.

${ }^{17}$ Para tanto, conferir: BRASIL. Supremo Tribunal Federal. Ação de Descumprimento de Preceito Fundamental $n^{\circ} 45$. Relator: Ministro Celso de Mello. RTJ, V. 200-01, p. 191.
} 
cotidiano dessa mesma sociedade. Corrupção, política como sinônimo de defesa de interesses meramente partidários, bem como burocratização estatal, são três componentes sociológicos que corroboram para fortalecer o mito do juiz Hércules no subconsciente coletivo e culminar na crescente judicialização das relações sociais (TEIXEIRA, 2012, p. 38).

Como enfrentar esse aparente paradoxo, tendo em vista a tarefa indiscutível do Judiciário de concretizar e tornar efetivos os direitos assegurados na constituição? A resposta encontra-se na função que deve ser exercida por esse Poder no contexto atual e que só pode ser adequadamente traçada quando o Legislativo não ignora a legística material - sob pena de os Tribunais “juridicizarem” a política, objetivando sanar a omissão do legislador ${ }^{18}$.

Atentando para essa “invasão do jurídico pelo político”, Kelsen sustenta que a corte suprema, no desempenho de sua missão, não pode ir além da invalidação da norma que à constituição se contrapõe. Ao tentar justificar a legitimidade da jurisdição constitucional perante a independência dos órgãos de produção normativa, Kelsen traça distinção entre a elaboração e a anulação de leis, limitando-se a esta o alcance da competência do tribunal constitucional.

É aqui que aparece a distinção entre a elaboração e a simples anulação das leis. A anulação das leis se produz essencialmente como aplicação da Constituição. A livre criação que caracteriza a legislação está aqui quase completamente ausente. Enquanto o legislador só está preso pela Constituição no que concerne ao seu procedimento - e, de forma totalmente excepcional, no que concerne ao conteúdo das leis que deve editar, e mesmo assim, apenas por princípios ou diretivas gerais -, a atividade do legislador negativo, da jurisdição constitucional, é absolutamente determinada pela Constituição. E é precisamente nisso que sua função se parece com a de qualquer outro tribunal em geral: ela é principalmente aplicação e somente em pequena medida criação do direito (KELSEN, 2003, p. 153).

No mesmo sentido, ao discorrer acerca da função normativa da interpretação, Betti (apud MEGALE, 2005, p. 157) sustenta que essa “[...] função não pode ser entendida como função legislativa. O intérprete vincula-se à lei, não se põe no lugar do legislador” . O autor busca a construção de uma "teoria científica da interpretação”, afastando-se do decisionismo kelseniano e estabelecendo quatro cânones hermenêuticos: 1) cânone da autonomia hermenêutica; 2) cânone da totalidade; 3) cânone da atualidade e 4) cânone da correspondência hermenêutica do sentido. De modo geral, o problema hermenêutico em Betti torna-se uma questão epistemológica, voltado à explicação do que é compreender (BETTI, 1995).

Em linha diametralmente oposta, Cappelletti sustenta que, do ponto de vista substancial,

\footnotetext{
${ }^{18}$ No Mandado de Segurança n. 26.603, o STF admitiu expressamente o seu papel político: “O exercício da jurisdição constitucional, que tem por objetivo preservar a supremacia da Constituição, põe em evidência a dimensão essencialmente política em que se projeta a atividade institucional do Supremo Tribunal Federal, pois, no processo de indagação constitucional, assenta-se a magna prerrogativa de decidir, em última análise, sobre a própria substância do poder”. Cf. BRASIL. Supremo Tribunal Federal. Mandado de Segurança $n^{o}$ 26.603. Relator: Ministro Celso de Mello. Julgado em: 31/06/2008. Disponível em: <www.stf.jus.br>. Acesso em: 24 mar. 2013.
} 
não é diversa a "natureza” do processo legislativo e do processo jurisdicional. Ambos constituem processos de criação do direito. A diferença entre eles se dá pelo fato de o último envolver o contraditório entre as partes, o que não ocorre no primeiro (CAPPELLETTI, 1999, p. 25-26).

Acreditamos, contudo, que é possível racionalizar o debate acerca da criatividade judicial, pois, ao invés de ser um defeito do qual há de se livrar o aplicador do direito, constitui uma qualidade essencial, que o intérprete deve desenvolver com coerência e que pode ser adequadamente limitada se, no processo legislativo, não for ignorada a contribuição trazida pela legística material ${ }^{19}$. A atividade criadora será legítima se devidamente fundamentada ${ }^{20}$, observar o procedimento cabível à espécie ${ }^{21}$ e estiver baseada em legislação fundada em efetiva avaliação de impacto (prospectiva e retrospectiva), impelindo o Poder Judiciário a atuar dentro dos limites estabelecidos constitucionalmente para o exercício de seu mister.

Desse modo, a legística material, ao buscar a melhoria de qualidade dos atos normativos, é instrumento hábil para o estabelecimento de um novo equilíbrio na relação entre os Poderes, potencializando a atividade legislativa (por exemplo, na implementação de políticas públicas) e evitando a imersão excessiva do Judiciário na tarefa de inovar, de forma geral e abstrata, no ordenamento jurídico.

\section{DA RESPONSABILIDADE DO LEGISLADOR NA DOUTRINA CLÁSSICA}

No que concerne à responsabilidade civil do Estado, a doutrina vem admitindo a reparação de danos causados a terceiros pela prática de atos administrativos, mas tem afastado a responsabilidade patrimonial de entes públicos em razão da prática de atos legislativos e judiciais. Em outras palavras, o Estado, em regra, não responde por prejuízos decorrentes de uma sentença ou de uma dada lei.

Não obstante, a jurisprudência dos tribunais superiores tem admitido a responsabilidade patrimonial do Estado por atos baseados em lei declarada, posteriormente, inconstitucional ${ }^{22}$, ou

\footnotetext{
${ }^{19}$ Considerando a amplitude da temática do controle de estruturas interpretativas e objetivando evitar uma análise superficial da matéria, remetemos o leitor para os seguintes artigos: COSTA, Rafael de Oliveira. Hermenêutica Constitucional e Hermenêutica Filosófica: Horizontes da Previsibilidade das Decisões Judiciais. In: Direito, Estado $e$ Sociedade, v. 44, p. 122-141, 2014; COSTA, Rafael de Oliveira. Horizontes Jusfilosóficos da Previsibilidade das Decisões Judiciais. In: Novos Estudos Jurídicos, v. 20, n. 2, p. 561-594, 2015.

${ }^{20}$ Cf. COSTA, Rafael de Oliveira. A Criatividade e a Responsabilidade no Ato de Julgar: Aportes da Hermenêutica Fenomenológica para a Jurisdição Constitucional. 201p. 2013. Tese (Doutorado em Direito) Faculdade de Direito, Universidade Federal de Minas Gerais, Belo Horizonte, 2013.

${ }^{21}$ Cf. COSTA, Rafael de Oliveira. A Criatividade, op. cit.

${ }^{22}$ Foi como decidiu o STJ no Recurso Especial n ${ }^{\circ}$ 571.645-RS, em voto do Relator Ministro João Otávio de Noronha: "2. Apenas se admite a responsabilidade civil por ato legislativo na hipótese de haver sido declarada a inconstitucionalidade de lei pelo Supremo Tribunal Federal em sede de controle concentrado”. Cf. BRASIL. Superior
} 
pelos danos decorrentes de leis com efeitos $\operatorname{concretos}^{23}$. Até mesmo a omissão estatal já tem sido admitida como fundamento de demandas indenizatórias contra a Fazenda Pública ${ }^{24}$. Fora dessas hipóteses o que se tem, contudo, é a não obrigação de indenizar.

A responsabilidade por leis inconstitucionais depende, no entanto, da prévia declaração do vício pelo Supremo Tribunal Federal. Se reconhecida a inconstitucionalidade, poderá ensejar a responsabilidade do Estado, porque o dano é causado por ato emitido contra a Constituição.

O Supremo Tribunal Federal há muito tempo já assentou a tese de que “o Estado responde civilmente pelo dano causado em virtude de ato praticado com fundamento em lei declarada inconstitucional”25.

Em relação às leis de efeitos concretos, a jurisprudência tem admitido a responsabilidade do Estado, uma vez que elas fogem às características da generalidade e abstração inerentes aos atos normativos. A lei de efeitos concretos, embora promulgada pelo Legislativo, constitui, quanto ao conteúdo, verdadeiro ato administrativo, permitindo a responsabilização civil do Estado ${ }^{26}$.

Por fim, o Estado deve ser responsabilizado pela omissão legislativa no caso de danos resultantes da inércia do legislador em editar normas destinadas a dar efetividade a direitos garantidos constitucionalmente, desde que haja fixação de prazo para elaboração de tal ato ou manifesta violação à razoabilidade ${ }^{27}$.

\section{DA NOVA RESPONSABILIDADE DO ESTADO-LEGISLADOR E DA ATUAÇÃO DA LEGÍSTICA COMO MEIO PARA A RELEGITIMAÇÃO DAS DECISÕES JUDICIAIS (PELA FORMA E PELO CONTEÚDO) DAS NORMAS}

Dentre as contribuições trazidas pela legística material para a melhoria da qualidade dos

\footnotetext{
Tribunal de Justiça. Recurso Especial $n^{\circ}$ 571.645/RS - Julgado em 21.09.2006. Disponível em: <www.stj.jus.br>. Acesso em: 31 out. 2015.

23 "Ato legislativo. Inconstitucionalidade - Responsabilidade civil do Estado. Cabe responsabilidade civil pelo desempenho inconstitucional da função de legislador". Cf. BRASIL. Supremo Tribunal Federal. Recurso Extraordinário $n^{\circ}$ 158.962-PB. Relator: Ministro Celso Mello - Julgado em 04/12/92. Disponível em: <www.stf.jus.br>. Acesso em: 24 maio 2015.

${ }^{24}$ Cf. BRASIL. Superior Tribunal de Justiça. Agravo Regimental no Agravo em Recurso Especial n $n^{\circ}$ 702.705-PB. Relator: Ministro Herman Benjamin. Julgado em 01/09/2015. Disponível em: <www.stj.jus.br>. Acesso em: 17 nov. 2015.

${ }^{25}$ Cf. BRASIL. Supremo Tribunal Federal. Recurso Extraordinário $n^{\circ}$ 153.464. Relator Ministro Celso de Mello. Julgado em 02/09/1992. Disponível em: <www.stf.jus.br>. Acesso em: 18 maio 2015.

${ }^{26}$ Cf. MELLO, Celso Antônio Bandeira de. Curso de Direito Administrativo. 17. ed. São Paulo: Malheiros, 2004.

${ }^{27}$ No Recurso Extraordinário ${ }^{\circ}$ 424.584-MG, o STF decidiu que, se o ato for praticado dentro da razoabilidade, não há que se falar em indenização: “[...] embora reconhecida a mora legislativa, não pode o Judiciário deflagrar o processo legislativo, nem fixar prazo para que o chefe do Poder Executivo o faça. Além disso, esta Turma entendeu que o comportamento omissivo do chefe do Poder Executivo não gera direito à indenização por perdas e danos”. Cf. BRASIL. Supremo Tribunal Federal. Recurso Extraordinário $n^{\circ}$ 424.584-MG. Relator para o acórdão Ministro Joaquim Barbosa Julgado em 17.11.2009. Disponível em: <www.stf.jus.br>. Acesso em: 18 maio 2015.
} 
atos normativos, a avaliação de impacto desponta como "ferramenta" singular, uma vez que atua em momentos distintos: prospectiva e retrospectivamente à aprovação do diploma normativo.

A avaliação prospectiva se vale de diversas metodologias, que vão desde a realização de simulações, até a avaliação dos possíveis efeitos que podem ser produzidos pelo ato normativo. De outro modo, a avaliação de impacto retrospectiva baseia-se na avaliação dos efeitos já produzidos pelo ato normativo. A sua adoção permite a edição de uma legislação de qualidade, o incremento do diálogo entre as fontes do direito e a possibilidade de limitar/diminuir custos administrativos (MENDES, 2001, p. 3).

Em assim sendo, se o legislador, no exercício da sua função, faz uma opção por normatizar uma dada situação de forma completamente diversa daquela indicada pela avaliação de impacto prospectiva, não produzindo os efeitos que dela são esperados (após a realização de avaliação de impacto retrospectiva), pode vir a ser responsabilizado pela sua opção?

Entendemos que a resposta é positiva. A partir de um detalhado levantamento de dados e da realização de uma criteriosa avaliação de impacto, torna-se plenamente possível responsabilizar o legislador, seja por uma opção equivocada à luz daquela que seria a melhor apontada pela avaliação de impacto, seja por eventuais falhas na realização da avaliação e que venham a gerar efeitos danosos para a sociedade.

Portanto, entendemos possível responsabilizar o legislador pelos efeitos da lei, uma vez que esta é (ou ao menos deveria ter sido) elaborada à luz de uma metodologia (avaliação de impacto) que possibilita uma decisão objetiva, informada e fundamentada. Em não atingindo os objetivos almejados, torna-se perfeitamente admissível ao Judiciário dar concretude aos direitos garantidos pela norma, uma vez que eventuais falhas não eximem o Executivo ou o Legislativo de suas responsabilidades e os direitos subjetivos não podem depender do alvedrio da administração pública.

Assim, quando a norma viola frontalmente os limites constitucionalmente estabelecidos, seja por não ter obedecido ao devido processo legislativo (que exige a realização da avaliação de impacto), seja porque a decisão tomada pelo legislador não obedece às diretrizes objetiva e fundamentadamente traçadas pela avaliação de impacto (que servem de balizas para o exercício da “discricionariedade política” pelo legislador), é possível responsabilizar aqueles que editaram o ato normativo, objetivando conter os abusos que vêm sendo praticados pelos parlamentos.

A título de exemplo, suponhamos que o Congresso Nacional aprove emenda constitucional, após detalhada avaliação de impacto prospectiva apontando os seus efeitos negativos, que venha a reduzir a maioridade penal. Passados mais de quatro anos da medida, 
verifica-se, por meio de avaliação de impacto retrospectiva, que a emenda não atingiu seus objetivos e ainda promoveu o aumento dos gastos públicos e danos irremediáveis, de natureza material e moral, a inúmeros adolescentes. Diante da inércia da Câmara dos Deputados e do Senado Federal, entendemos que, se dito diploma não produziu quaisquer de seus regulares efeitos aferidos após a realização da avaliação de impacto retrospectiva -, pode o legislador ser responsabilizado, tendo em vista que a atividade legislativa é, antes de tudo, uma função pública que possui limites constitucionalmente traçados para seu exercício.

Não bastasse, entendemos que as potencialidades da avaliação de impacto são ainda mais abrangentes: ela permite delimitar a incursão do Judiciário na “discricionariedade política” do legislador, servindo de base para a responsabilidade decorrente do exercício da função legislativa. Inúmeros abusos têm sido praticados sob a alegação de que o legislador possui ampla discricionariedade para editar atos normativos, esquecendo-se que o exercício da função legislativa não pode fugir dos parâmetros previamente traçados pela Constituição. O Judiciário, nesse limiar, deve estar ciente do seu papel.

Com efeito, como ocorre em diversas outras temáticas que envolvem a responsabilidade do Estado, podemos equiparar o comportamento da jurisprudência ao de um pêndulo: em um dado momento, pende-se para a total irresponsabilidade; em um segundo momento, para a responsabilização excessiva; até que, por fim, o Judiciário encontra um meio-termo na sua atuação. Acreditamos que este deva ser o futuro da responsabilização do legislador no exercício da sua função precípua, levando-se em consideração os novos horizontes trazidos pela avaliação de impacto. Isso porque os instrumentos desenvolvidos pela legística pretendem incorporar uma nova racionalidade ao modo de decidir, incutindo no juiz e no legislador, por meio da avaliação de impacto, uma nova consciência dos efeitos econômico-sociais de suas decisões (WINTGENS, 2000, p. 149), a permitir um novo equilíbrio na seara da separação dos poderes. Em outras palavras, busca-se afastar a promulgação de diplomas normativos meramente simbólicos, promovendo a elaboração de normas efetivas e eficazes (horizontal, vertical e diagonalmente), de modo a legitimar a atuação do Legislativo e do Judiciário mediante o diálogo legislação-racionalidade-aplicação da norma e a consolidação do fenômeno jurídico como uno e indivisível.

Em suma, partindo de um ponto de vista hermenêutico, a avaliação de impacto legislativo pode servir como importante "ferramenta” para a fixação de limites à função legislativa e para a melhoria da qualidade da legislação, relegitimando as decisões judiciais pela forma e pelo conteúdo das proposições normativas que lhes servem de substrato. 


\section{CONCLUSÕES}

A legística, enquanto área do conhecimento que se ocupa do fazer dos atos normativos, almeja aprimorar a qualidade da legislação, levando o legislador, antes de positivar a norma jurídica, a pensá-la sob uma perspectiva crítica, para solução dos conflitos existentes.

Assumindo, com Wintgens, que todo raciocínio jurídico parte de um "ponto de vista hermenêutico”, a legística material assume um papel relevantíssimo não só no exercício da função legislativa, mas também no exercício da função jurisdicional, uma vez que permite o diálogo legislação-racionalidade-aplicação da norma e a consolidação do fenômeno jurídico como uno $e$ indivisível.

Nesse contexto, a proposta de repensar o problema da racionalidade e legitimidade das decisões judiciais sob a égide da legística material e a partir de um "ponto de vista hermenêutico" revela-se de grande utilidade para uma compreensão mais profunda do fenômeno do poder criativo do direito pelo Judiciário, pois inaugura um novo enfoque que prioriza o questionamento acerca do próprio papel da legística (não mais limitada ao estudo de métodos adequados para a elaboração da norma) e da hermenêutica.

O que se observa na atualidade é que, quando a legística não é "levada a sério”, o Judiciário amplia o seu campo de atuação e a sua postura criativa torna-se ainda mais evidente. Contudo, é possível racionalizar o debate acerca da criatividade judicial, porque a atividade criadora é legítima quando devidamente fundamentada, baseando-se em uma legislação que legitima as decisões judiciais, pela forma e pelo conteúdo. Em outras palavras, a legística material, quando acompanhada da avaliação de impacto, pode contribuir decisivamente para uma adequada delimitação da função juspolítica exercida pelos tribunais, ajudando a estabelecer as atribuições dos Poderes constituídos e a determinar o papel do Judiciário e do Legislativo no contexto hodierno.

Ademais, se o legislador, no exercício da sua função, faz uma opção por normatizar uma dada situação de forma completamente diversa daquela indicada pela avaliação de impacto prospectiva, não produzindo os efeitos dela esperados, deve ser responsabilizado pela sua opção. Isso porque, quando a norma viola frontalmente os limites constitucionalmente estabelecidos, seja por não ter obedecido ao devido processo legislativo (que exige a realização da avaliação de impacto), seja porque a decisão tomada pelo legislador não obedece às diretrizes objetiva e fundamentadamente traçadas pela avaliação de impacto (que servem de balizas para o exercício da “discricionariedade política” pelo legislador), deve-se responsabilizar aqueles que editaram o ato normativo, objetivando conter os abusos que vêm sendo praticados pelos parlamentos.

Em suma, partindo de um ponto de vista hermenêutico, a avaliação de impacto legislativo 
pode servir como importante “ferramenta” para a fixação de limites à função legislativa e melhoria da qualidade da legislação, (re)legitimando as decisões judiciais pela forma e pelo conteúdo das proposições normativas que as embasam, sem prejuízo da responsabilização do legislador pela elaboração de diplomas que não produzem os efeitos deles esperados.

\section{REFERENCIAS}

BETTI, Emílio. Teoria Generale della Interpretazione. Milano: Giuffrè, 1995.

CANOTILHO, Joaquim José Gomes. Os impulsos modernos para uma teoria da legislação. In: Cadernos de Ciência da Legislação. Oeiras, n. 1, p. 7-14, abr.- jun. 1991.

CAPPELLETTI, Mauro. Juízes Legisladores? Trad. Carlos Álvaro de Oliveira. Porto Alegre: Sergio Antonio Fabris Editor, 1999.

COSTA, Rafael de Oliveira. Hermenêutica Constitucional e Hermenêutica Filosófica: Horizontes da Previsibilidade das Decisões Judiciais. In: Direito, Estado e Sociedade, v. 44, p. 122-141, 2014.

. Horizontes Jusfilosóficos da Previsibilidade das Decisões Judiciais. In: Novos Estudos Jurídicos, v. 20, n. 2, p. 561-594, 2015.

CRUET, Jean. A vida do direito e a inutilidade das leis. Salvador: Livraria Progresso, 1956.

DELLEY, Jean-Daniel. Pensar a Lei: uma introdução a um procedimento metódico. In: Cadernos da Escola do Legislativo. Belo Horizonte, v. 7, n. 12, p. 101-143, jan./jun. 2004.

FLORES, Imer B. The Quest of Legisprudence: Constitutionalism v. Legalism. In: WINTGENS, Luc J. (Org.) The Theory and Practice of Legislation: Essays in Legisprudence. [s.l.] Ashgate, 2005, p. 26-51.

JELLINEK, G. Reforma y Mutación de la Constitución. Trad. Christian Förster. Madrid: Centro de Estudios Constitucionales, 1991.

. Teoria General del Estado. 2. ed. Trad. Fernando de Los Rios Urruti. México: Fundo de Cultura Económica, 2000.

HESSE, Konrad. A força normativa da Constituição. Trad. Gilmar Ferreira Mendes. Porto Alegre, Sergio Antônio Fabris, 1991.

KELSEN, Hans. Jurisdição constitucional. Trad. Maria Ermantina Galvão. São Paulo: Martins Fontes, 2003.

LAFUENTE BALLE, José María. La judicialización de la interpretación constitucional. Madri: COLEX, 2000. 
LASSALLE, Ferdinand. A Essência da Constituição. Trad. Walter Stönner. Rio de Janeiro: Liber Juris, 1985.

MEGALE, Maria Helena Damasceno e Silva. A Teoria da Interpretação Jurídica: um Diálogo com Emilio Betti. In: Revista Brasileira de Estudos Políticos. Belo Horizonte: Imprensa Universitária da UFMG, nº 91, jan.-jun. 2005.

MENDES, Gilmar. Questões Fundamentais de Técnica Legislativa. In: Revista Diálogo Jurídico. Salvador: Diálogo Jurídico, 2001. Ano 1, Vol. 1, N. 5, p. 3-17.

PECZENIK, Aleksander. On law and reason. 2. ed. [S. 1.]: Springer, 2009.

ROSS, Alf. Teoria de las fuentes del derecho. Madrid: Centro de Estudios Políticos y constitucionales, 1999.

SCHMITT, Carl. A crise da democracia parlamentar. Trad. Inês Lobhauer. São Paulo: Scritta, 1996.

. La defensa de la constitución. 2. ed. Trad. Manuel Sanchez Sarto. Madri: Tecnos, 1998.

SILVA, José Afonso da. Processo Constitucional de Formação das Leis. São Paulo: Malheiros, 2006.

STRECK, Lenio Luiz. Verdade e Consenso: Constituição, hermenêutica e teorias discursivas. Rio de Janeiro: Lumen Juris, 2006.

TEIXEIRA, Anderson Vichinkeski. Ativismo judicial: nos limites entre racionalidade jurídica e decisão política. Revista Direito GV, Vol. 8, n. 1, p. 37-57, 2012.

VILLEY, Michel. A formação do pensamento jurídico moderno. São Paulo: Martins Fontes, 2005.

WALDRON, Jeremy. A dignidade da legislação. São Paulo: Martins Fontes, 2003.

WINTGENS, Luc J. La législation entre science et politique: Éléments pour une approche légisprudentielle du droit. Revue interdisciplinaire d'études juridiques. Bruxelas: Facultés Universitaires Saint-Louis, 2000, 115-155.

. Legisprudence as a New Theory of Legislation. Ratio Juris - An International Journal of Jurisprudence and Philosophy of Law, V. 19, n. 1, p. 1-25, 2006.

; LALANA, Angel Daniel-Oliver (Ed.). The Rationality and Justification of Legislation Essays in Legisprudence. Heidelberg: Springer, 2013.

\section{THE ROLE OF LEGISTICS IN (RE)LEGITIMATION OF JUDGMENTS AND IN BALANCING THE JUSPOLITICAL FUNCTIONS OF COURTS}




\begin{abstract}
This study seeks to rethink the problem of rationality and legitimacy of judicial decisions under the contributions of legistics, revealing useful for a deeper understanding of the phenomenon of the creative power of Judiciary and inaugurating a new approach that prioritizes the questioning about the proper role of legistics (no longer limited to study methods). Bearing in mind impact assessment and from an "hermeneutical point of view", we hold that legistics decisively contributes to an adequate delineation of the juspolitical function performed by courts, helping to establish the duties of constituted Powers and the current role of Judiciary and Legislative, without disregarding the responsibility of legislators when drafting normative propositions that do not produce the expected effects.
\end{abstract}

\title{
KEYWORDS
}

Legistics. Juspolitical function of courts. Legislator's responsibilities. 